\title{
Adrenocorticotropic Hormone Deficiency
}

National Cancer Institute

\section{Source}

National Cancer Institute. Adrenocorticotropic Hormone Deficiency. NCI Thesaurus.

Code C120433.

Subnormal concentration of adrenocorticotropic hormone (ACTH) resulting in decreased secretion of cortisol by the adrenal gland. 